\title{
ENSEÑANZA Y UTOPÍA. INICIATIVAS ASOCIADAS EN LA ARQUITECTURA MODERNA URUGUAYA
}

\author{
William Rey Ashfield \\ Universidad de la República de Uruguay
}

\begin{abstract}
RESUMEN
La inserción de ideas utópicas en la arquitectura moderna uruguaya, durante la primera mitad del siglo $X X$, resulta comprobable en programas de alto interés social, como la enseñanza y su posibilidad de desarrollo en infraestructuras edilicias diferentes, entendidas estas como ámbitos para la formación de un hombre nuevo, en fuerte comunión con la naturaleza. Un ejemplo ilustrativo de esa búsqueda utópica lo constituye la idea de Parques Escolares, desarrollada por el filósofo Carlos Vaz Ferreira y materializada a través de distintos anteproyectos arquitectónicos, a finales de la década de 1920. Algunas obras realizadas en los años de 1930, todavía recogen algunas de estas ideas, aun cuando ya no resulten proyectos directamente asociados a los Parques Escolares: se trata de las llamadas Escuelas Experimentales, proyectadas por el arquitecto Juan Scasso.
\end{abstract}

Palabras clave: parques escolares, enseñanza, naturaleza, utopía, proyectos de arquitectura

\section{ABSTRACT}

The emergence of utopian ideas in modern Uruguayan architecture in the first half of the 20th century took shape in programmes of significant social interest, for example in education and the possibilities of applying them in different architectural infrastructures, which were understood as areas for the creation of a new man at one with nature. An illustrative example of this search for utopia is the Parques Escolares (school parks) concept developed by the philosopher Carlos Vaz Ferreira and which took material form in a number of preliminary architectural plans in the late 1920s. Some of the works carried out in the 1930s continued to put forward some of these ideas, even if they no longer had any direct link with the Parques Escolares projects. These works included the so-called Escuelas Experimentales (experimental schools), designed by the architect Juan Scasso.

Keywords: school parks, teaching, nature, utopia, architectural projects

La arquitectura moderna uruguaya tuvo importantes convergencias con la idea de utopía, entre las décadas de 1920 y 1950. Sin embargo, más que en la dimensión urbana - si bien pueden rastrearse algunos intentos a esa escala, estos proyectos quizás estén más cercanos a lo ideológico que a lo utópico' - es necesario analizar dicha utopía dentro de ciertos programas de arquitectura pública, fundamentalmente orientados a la salud y a la enseñanza.
Entre los primeros, constituye un singular ejemplo el Ilamado Centro Médico, proyectado a partir de una ley promulgada en octubre de 1926 que autorizaba la creación de la Facultad de Odontología y otros dos edificios², concebidos en proximidad y conformando una suerte de "ciudad de la salud". Las formas que adquiere el conjunto y su disposición planimétrica, su destino social y pedagógico así como su concepción igualitarista de acceso a los programas sanita- 
rios, forman parte de una utopía que, aunque controlada, resulta suficiente para poner en crisis los discursos historiográficos que han negado el vínculo entre esta y la producción arquitectónica de entonces ${ }^{3}$. Lo mismo podríamos decir de ciertos programas sociales, con fuerte énfasis en materia de sanidad, como lo fue el plan de Centros de Barrio ${ }^{4}$, al que estuvieron vinculados importantes arquitectos modernos como Juan Scasso y J. H. Domato.

Más clara y contundente es, en cambio, la relación de la arquitectura moderna uruguaya -en particular la de la primera mitad del siglo $X X$ - con programas de enseñanza que cuestionan y replantean las líneas pedagógicas más tradicionales en esta materia. Desde este punto de vista, es necesario analizar las posibles correspondencias entre la propuesta arquitectónica y una dimensión utópica cuyo propósito será el alcance de un hombre nuevo, mejor preparado para la vida y, al mismo tiempo, en mayor comunión con la naturaleza.

\section{Los Parques-Escolares}

En una interesante conferencia dictada en 1927, Carlos Vaz Ferreira ${ }^{5}$ - figura central de la filosofía uruguaya en el siglo XX -, afirmaba la necesidad de una concepción alternativa de la escuela pública a partir de un nuevo programa edilicio y un contexto ambiental diferente. Se trataba de una organización escolar capaz de llegar a un muy elevado número de niños, integrados todos dentro de un gran ámbito verde, que rodearía a diferentes edificios escolares. El autor del proyecto especificaba tanto las características del terreno -una suerte de isla arcádica, definida en sus diferentes detalles paisajísticos y ambientales-, como las arquitecturas correspondientes que deberían ser de extrema simplicidad formal y material, en consonancia "con el espíritu moderno". Las dimensiones del proyecto y la enorme concentración de población infantil dentro de un mismo sitio, conformaba de por sí una propuesta asombrosa, de una escala difícil de imaginar en la época. Aun así, una parte importante del espectro político uruguayo estuvo dispuesto a considerarla y debatirla, fenómeno interesante de apertura a lo nuevo que ayuda a explicar también el creciente desarrollo de la arquitectura moderna estatal, en tempranas décadas del siglo.
En realidad, Vaz Ferreira había planteado antes esta iniciativa ${ }^{6}$, en ocasión de integrar la Dirección de Instrucción Primaria, donde los problemas de la edificación escolar eran, por entonces, bastante acuciantes. Pero si bien el estado uruguayo asumía la necesidad de aportar y recibir ideas en relación a programas y a nuevas infraestructuras escolares, veía compleja la ejecución de esta propuesta en razón de una estricta solución de transporte. Sin embargo, en 1927 - para entonces habían cambiado radicalmente las coordenadas del transporte urbano en Montevideo - el proyecto comienza a ganar visos de realidad con el apoyo del Ministro de Instrucción Pública, Enrique Rodríguez Fabregat, quien toma con agrado la propuesta y le hace ajustes para su más eficiente materialización. Esta figura política hace pública la idea', al tiempo que promueve el desarrollo de tres anteproyectos interpretativos, que se materializarían dentro del Departamento de Arquitectura del Ministerio de Obras Públicas (Figs. 1 y 2).

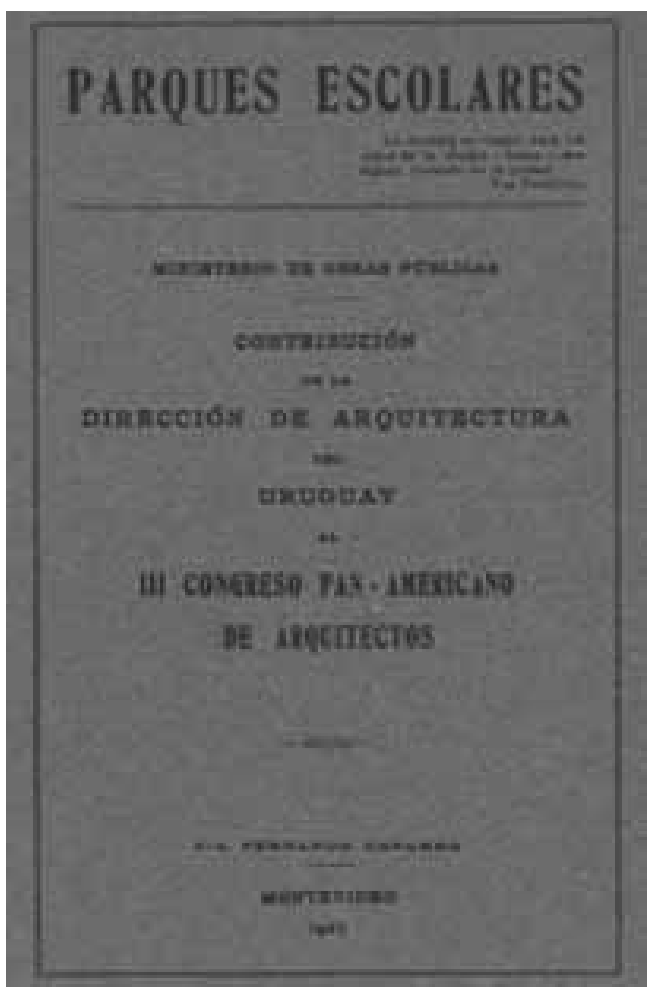

Fig. 1. Publicación del Ministerio de Obras Públicas, presentada en el III Congreso Panamericanos de Arquitectos, en Buenos Aires. 1927 


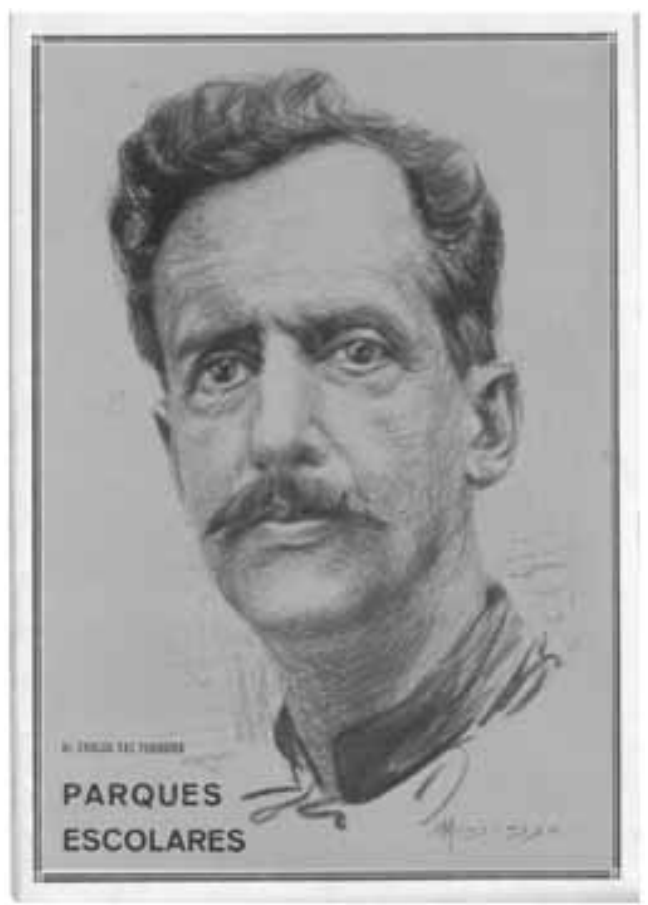

Fig. 2. Folleto publicado a iniciativa de la Editorial Gutenberg

En 1929, cuando Le Corbusier dicta sus conferencias en Montevideo, hace especial énfasis en la importancia de este proyecto, concebido por Vaz Ferreira, sosteniendo al respecto:

Es magnífico. Si se lleva a cabo Uds. podrán ofrecer al mundo entero una realización soberbia de altas proporciones humanas. Esta obra marcará una etapa pedagógica y será decisiva para el destino de la cultura y de la raza del Uruguay. Aunque haya adversarios encarnizados de los parques escolares y timoratos que tiemblen de miedo ante la originalidad auténtica de ese proyecto, no importa: ellos quedarán en una situación tan mezquina y ridícula como los adversarios de Pasteur o de Galileo ante la ciencia actual. Repito que tengo la certeza de que los buenos principios triunfan después de las luchas que provocan. Esto forma el eje del credo de mi optimismo actuante. ${ }^{8}$

La propia argumentación del arquitecto suizo habla a las claras de esa dimensión utópica. Se trata para él de un proyecto "de altas proporciones humanas" que se fundamenta en "buenos principios" y, por sobre todo, que estos "triunfan después de las luchas que provocan".
Es decir que los parques-escolares se presentan como una idea algo subversiva frente al orden imperante de los viejos programas de enseñanza y sus correspondientes arquitecturas, exigiendo de manera alternativa un nuevo hábitat para su desarrollo.

A pesar este gran impulso y respaldo de opiniones, el proyecto fue naufragando lentamente hasta ser abandonado. Alguna de las argumentaciones en su contra refirieron levemente a lo utópico del mismo, bajo el entendido de que si bien se trataba de un propósito con buenas intenciones era, sin embargo, falto de realismo. Como es sabido, tal valoración de la utopía como proyecto de difícil realización se instala en una buena parte de los discursos modernos del siglo XX - incluido Uruguay - como deriva del uso que Carlos Marx hiciera del mismo al definir el carácter de las propuestas socialistas anteriores a su modelo. Esta equívoca aplicación del término, reiterada históricamente por otros autores, llevó a que muchas ideas utópicas, verdaderamente subversivas del cuerpo ideológico imperante, fueran entendidas como opciones inútiles o de escaso valor práctico. En paralelo, muchos proyectos utópicos extremaron definiciones y detalles de materialización y operativa, como manera de evitar caer en tal definición, esgrimiendo argumentaciones de base cientificista - fisiológicas, psicológicas, etc. -, que ocultaban, muchas veces, el real deseo de construir un proyecto alternativo más ambicioso, con vocación de metas superiores como ser la construcción de un hombre y una sociedad nueva. Esta raíz utópica estaba, precisamente, en el proyecto de los Parques-Escolares propuestos por Vaz Ferreira, aunque teñido de otras explicaciones que, si bien importantes, posiblemente no constituían la razón última de su propuesta.

\section{Mens sana in corpore sano}

"No hay solo aquí una cuestión de edificios: hay la cuestión fundamental de la salud y la vida de un pueblo", sostiene Rodríguez Fabregat ${ }^{9}$, en directo apoyo al proyecto del filósofo. Luego subraya: "El ideal de una raza fuerte y sana - mens sana in corpore sano - sólo puede conseguirse a condición de que el niño sea sano y vigoroso (...). Las ciudades no han sido construidas en vista de esa aspiración" ${ }^{10}$. Para esto, el ministro en- 
tiende que el programa escolar podría remediar, en parte, los problemas de la ciudad: "Instálense las escuelas urbanas en los alrededores [de la ciudad], o en pleno campo si es posible. Así, los niños de las ciudades tendrán lo que en ellas falta, por lo menos a la gran mayoría: aire, luz, sol, espacio libre, horizontes abiertos, diario e íntimo contacto con la naturaleza". El discurso parece centrarse en la imposibilidad de las ciudades de aportar ese ambiente ideal, limitado por las rígidas condiciones de localización y por padrones de acotadas dimensiones.

El propio Vaz Ferreira hace críticas concretas en este sentido, al referirse a las escuelas de su proyecto en el verde: " ... ya no hay más paredes próximas, ya no hay más necesidad de hacer más de un piso. Ya no hay ese horror de salones que no pueden dar a la luz ni tener comunicación bien directa con el aire. Ya no hay que hacer corredores, ni pozos de luz y de aire, ni patios en condiciones que solo la costumbre nos hace encontrar tolerables." Tales observaciones están en línea con lo expresado en Montevideo por Le Corbusier: "Acabar de una vez por todas con ese tipo de escuela inhumana que guarda traidoramente un enjambre de niños en una sala (...) pequeña, sombría, triste, deprimente y hasta húmeda y malsana." ${ }^{\prime 11}$

En las anteriores apreciaciones es posible verificar, además del valor inherente al contacto con la naturaleza, una crítica a la edificación montevideana y, de manera indirecta, a las lógicas de agrupación catastral que impone la ciudad de acuerdo al inevitable sistema de medianería. Es de recordar que en esos mismos años - y luego de un extenso proceso de discusiones - se aprueba la llamada Ley de Higiene de la Vivienda ${ }^{12}$, que parece recoger las mismas preocupaciones sanitarias planteadas por Vaz Ferreira para las escuelas.

Pero si la defensa del contacto con la naturaleza encuentra argumentaciones sólidas, de base cientificista - no olvidar el peso que el positivismo tuvo en el Uruguay de la primera mitad del siglo XX - en la dimensión física y sicológica de los niños, también hay argumentos culturales de enorme importancia que forman parte de la mirada integral, acerca de la enseñanza, que tuvo Vaz Ferreira. Al respecto afirmaba en 1927:
Es que no hay educación física completa, sin la ejercitación en las actividades del trabajo. No es forzoso ni bueno tampoco que cada hombre sepa hacer todos los trabajos, incluso los especializados. Pero todo hombre para ser hombre tiene que saber hacer lo más humano y lo más general del trabajo. Tiene que saber trabajar la tierra, tiene que saber cavar, tiene que saber plantar, tiene que ser un poco carpintero, tiene que ser un poco albañil tiene que saber manejar una azada, manejar un hacha, un serrucho. Eso produce el hombre completo... ${ }^{13}$

Es en este último aspecto - la búsqueda de un "hombre completo" u hombre nuevo - donde reside la dimensión más utópica y, posiblemente más importante, del proyecto. Más que resolver una cuestión de orden sanitario e higienista aprender sanamente en el verde - es en la capacidad de enfrentar y convivir con la naturaleza, superando los límites que esta impone, donde se centra su principal objetivo. Se trata de un discurso que, cuidando de no ubicarse en una retaguardia conceptual, hace alusión a los excesos de profesionalismos y tecnicismos de la civilización contemporánea. Los niños de los parques escolares podrían reconocer su verdadera dimensión humana "haciéndose" en la naturaleza, como en una verdadera arcadia de trabajo y aprendizaje, a la manera del Walden de H. D. Thoreau o quizá -tomando un ejemplo más directo- como en la propia quinta de Vaz Ferreira, donde sus hijos aprendieron ${ }^{14}$ en medio de un rústico jardín, en natural movimiento ${ }^{15}$. El gran sentido de esa utopía -el hombre completo, el hombre nuevono debía manifestarse como centro del discurso -aunque aflorara pocas y controladas veces- porque la utopía ya era vista como el lugar de lo imposible. Las razones de higiene y sanidad física y sicológica, en cambio, estaban en el mejor momento histórico de apreciación y valoración, lo que explica el lugar central que alcanzaron en la trama argumental de estos "parques escolares".

\section{Tres anteproyectos}

En la búsqueda de una posible viabilidad de esta propuesta, durante la titularidad de Rodríguez Fabregat como Ministro de Instrucción Pública, se producen tres proyectos interpretativos en el marco del entonces llamado Ministerio de Obras Públicas. Los tres fueron publicados con sus gráficos y memorias correspondientes en un 
documento presentado ante el Congreso Panamericano de Arquitectos, a realizarse en Buenos Aires en 1927, lo que da muestra del sentido moderno que este tenía entonces. No obstante, las propuestas serían bastante distintas, con manejos alternativos de recursos de composición y proyectos edilicios.

Uno de ellos, el presentado por el arquitecto Fernando Capurro, expone una comprensión todavía muy académica, que parece incluso establecer lazos con proyectos históricos como el de las Salinas de Chaux, de C. N. Ledoux. Aunque se trata de un proyecto evolutivo, este se visualiza en su totalidad a partir de una propuesta radial, bastante próxima al concepto de panóptico. Tres edificios importantes se ubican en el centro, tal como lo planteara Vaz Ferreira: un edificio museístico ubicado en el eje ordenador del territorio, al que le sigue un edificio de asistencia médica, también axial. A los costados del eje se completa con dos construcciones también importantes en tamaño y función: el edificio de la Escuela Normal Mixta y la Administración. En derredor de estos se ubicaban las escuelas, ordenadas en 8 áreas verdes que completaban, cada una de ellas, los seis años de la formación primaria; por esto contaban con 6 edificios de aulas y un pabellón central que incluía laboratorios, sala de los maestros, servicio de leche, cocina y talleres de trabajos manuales. Importa destacar el valor asignado a los llamados "campos de experimentación", donde se identifican grandes espacios destinados a granja, vivero, bosques y talleres. Es este componente de la enseñanza un elemento fundamental en el proyecto de Vaz Ferreira, pudiendo visualizarse en la correspondiente asignación de espacio (Figs. 3, 4 y 5).

El proyecto del arquitecto Roberto Bianchi, en cambio, apuesta a una organización más orgánica y menos comprometida con un orden geométrico. No obstante, se identifica una jerarquía de localización para los edificios más importantes: de museos y conferencias, de asistencia médica, de administración, escuela normal mixta y cuartel de bomberos. Si bien cuenta con una zona llamada campo de experimentación este pierde protagonismo en relación al proyecto de Capurro, pero dispone de una mejor distribución de las tareas rurales en el espacio próximo a los

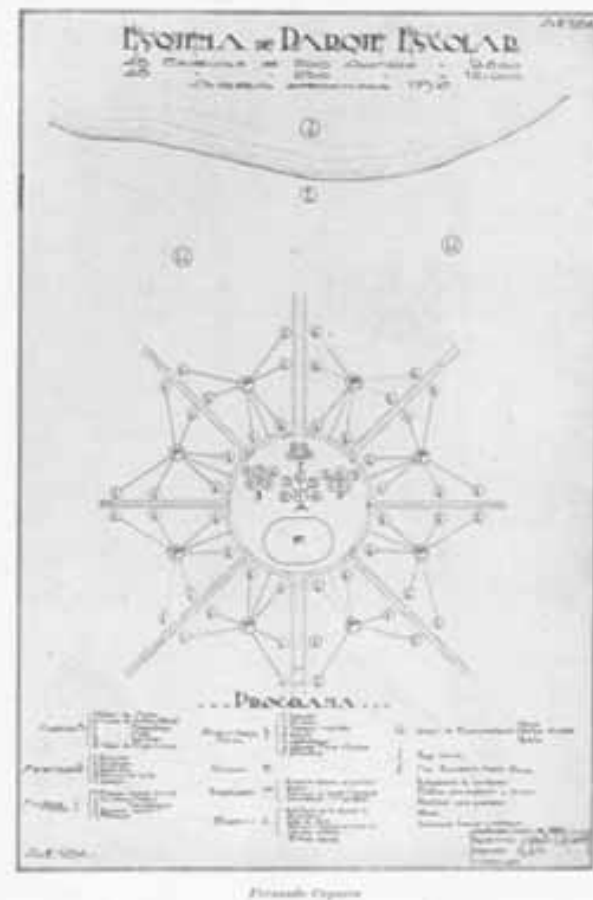

Fig. 3. Anteproyecto de parque escolar, del Arq. Fernando Capurro. Esquema General

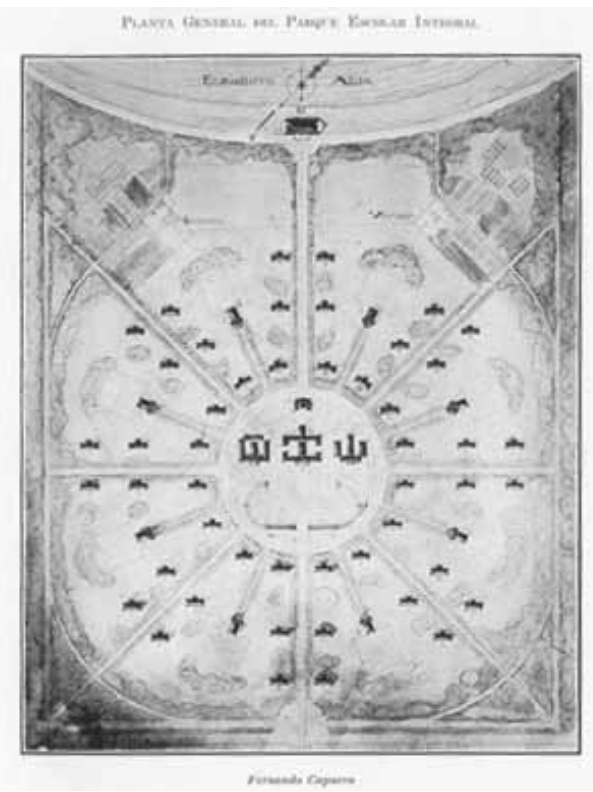

Fig. 4. Anteproyecto de parque escolar, del Arq. Fernando Capurro. Planta general 


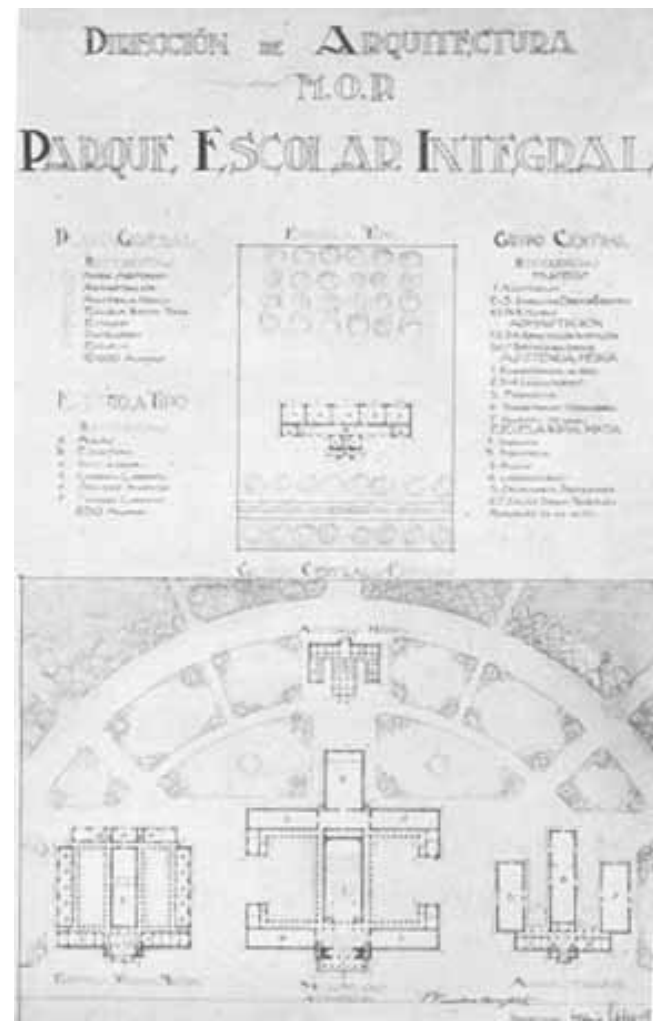

Fig. 5. Anteproyecto de parque escolar. Arq. Fernando Capurro. Plantas de edificios centrales

edificios escuela. Estos se agrupan en diez unidades, con cuatro edificios cada una. Las arquitecturas, al igual que en el proyecto del arquitecto Capurro se ven algo determinadas por un cierto academicismo, aun cuando los lenguajes formales se inscriban dentro del camino más propio de la modernidad (Figs. 6 y 7 ).

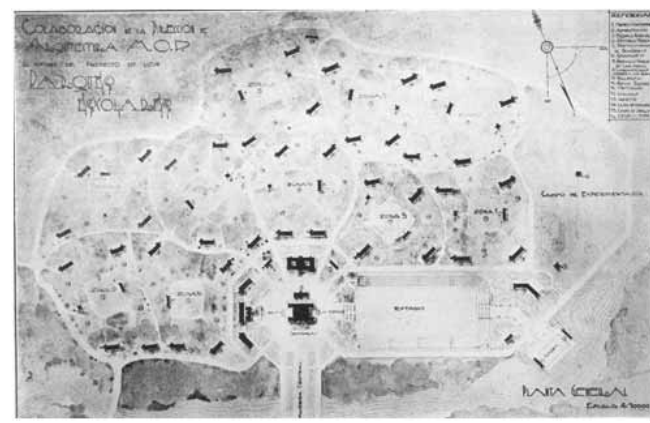

Fig. 6. Anteproyecto de parque escolar. Arq. Roberto Bianchi. Planta General

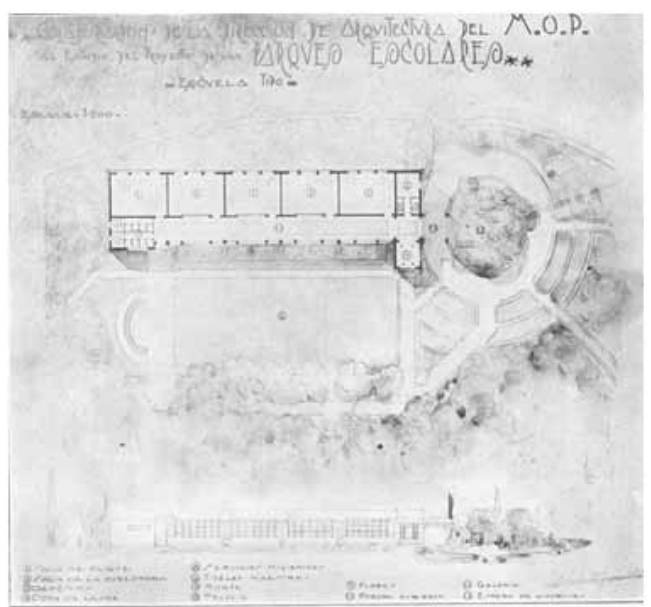

Fig. 7. Anteproyecto de parque escolar. Arq. Roberto Bianchi. Pabellón de clase

Finalmente, el anteproyecto presentado por el arquitecto Raúl Federici, constituye una propuesta más limitada en capacidad - ha sido es-

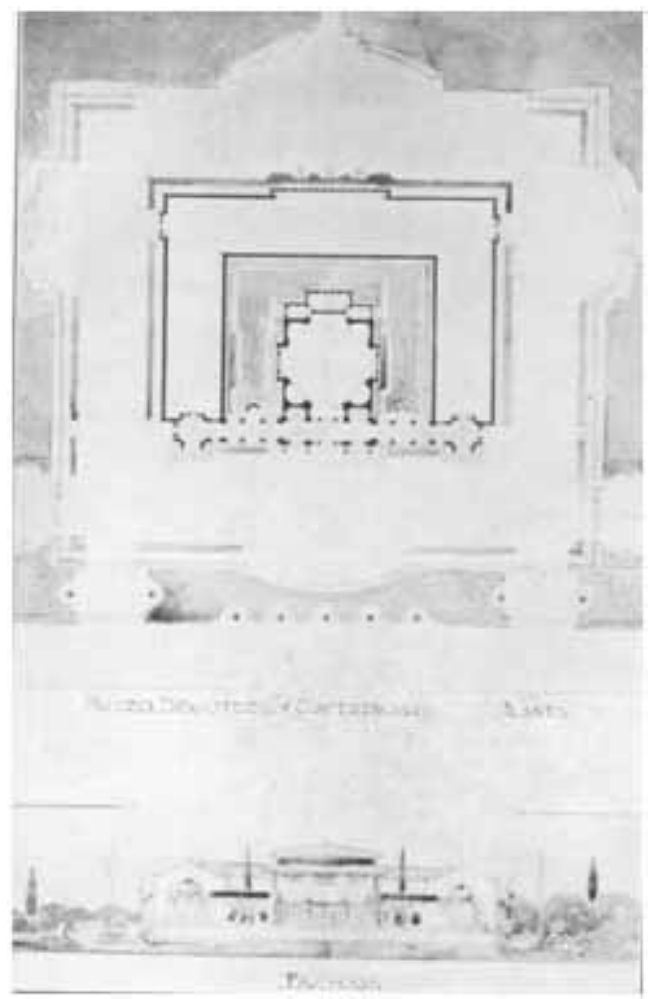

Fig. 8. Anteproyecto de parque escolar. Arq. Raúl Federici. Edificios Centrales 
tudiada para un número de 3000 niños, frente a las anteriores que consideraron un número de 10.000, tal como lo planteaba Vaz Ferreira-y en número de edificios ya que solo alcanza a once edificios-escuela, además de los correspondientes edificios centrales. Quizá esta sea una propuesta más ideológica que utópica, cercana a un empirismo poco innovador (Figs. 8 y 9).

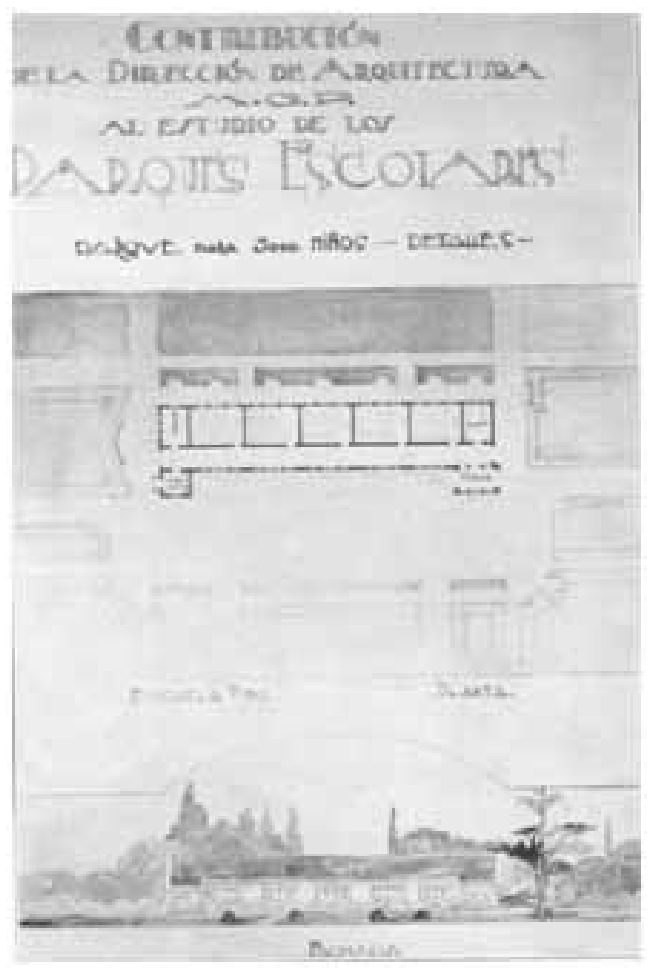

Fig. 9. Anteproyecto de parque escolar. Arq. Raúl Federici. Pabellón de clases

Todos los proyectos han evaluado las condiciones naturales del terreno - aun cuando se tratara de terrenos imaginarios y no reales -, como ser la presencia del agua, las afectaciones del clima y la generación de microclimas mediante protecciones de bosques; también la mejor ubicación de los edificios de acuerdo a las orientaciones y al giro helio-trópico, todos factores que no siempre pueden resolverse satisfactoriamente en predios urbanos. Hay en todos estos proyectos un espíritu académico que resulta propio de los ejercicios de enseñanza desarrollados, por entonces, en la facultad de arquitectura. En al- gunos de ellos la impronta edilicia es más moderna -como en el caso de Bianchi- mientras que en otros - como Federici - las referencias historicistas se muestran protagónicas en la definición de los edificios centrales. Son tiempos, como se ha dicho antes, donde la matriz académica es todavía fuerte, aun cuando distintos arquitectos uruguayos contemporáneos estén investigando, por entonces, nuevos y más alternativos caminos proyectuales.

\section{La escuela "de la vida por la vida"}

En 1926, en tiempos cercanos a las discusiones sobre los parques escolares propuestos por Vaz Ferreira, una maestra llamada Olympia Fernández iniciaba un viaje por distintos países europeos - Holanda, Bélgica, Suiza, España y Francia - con el propósito de formarse en el área de filosofía y la psicología. En Bélgica, en L'Ecole de L'Hermitage, Olympia se vincularía con el Dr. Ovide Decroly, famoso pedagogo de quien resultaría una verdadera seguidora de sus lineamientos doctrinales. Regresada al país, buscará contagiar las ideas del médico belga en el ámbito local, hasta conseguir la apertura de una pequeña escuela donde aplicar la nueva metodología de enseñanza. Era entonces el año 1927 y había un espacio importante -especialmente durante el Ministerio de Rodríguez Fabregat - para la innovación en materia de enseñanza.

Olympia Fernández haría, sin embargo, una verdadera adaptación del método decrolyano a la realidad de nuestro país, tal como lo expusiera el arquitecto Juan Scasso ${ }^{16}$, autor del proyecto para su nueva escuela, en el barrio Malvín. Se trataba entonces de un sueño que, mediante un fuerte pragmatismo - diferente en su escala al ambicioso plan de Vaz Ferreira -, materializaría lo que aquella maestra uruguaya llamó: "la escuela de la vida por la vida". La dupla de estos dos técnicos, Olympia Fernández y Juan Scasso ${ }^{17}$, permitió un inteligente y ajustado maridaje entre ejercicio docente, arquitectura y naturaleza.

Juan Scasso había iniciado antes una cierta experiencia proyectual en edificios escolares, desarrollando un proyecto antecedente para la Dirección de Escuelas, en el barrio Manga, sobre el Camino Maldonado: 
Me planteé entonces, el dilema de cómo debería ser. La escuela, me dije, debe abrirse hacia el exterior, en lugar de las pequeñas ventanas verticales hasta entonces; planteé las ventanas horizontales, de modo de que los niños, unos al lado del otro, pudieran ver hacia afuera en una extensión grande, volcando la naturaleza hacia adentro. Si el niño no pudiese salir debido al mal tiempo, siempre estará mirando hacia afuera. Y frente a esa naturaleza se da la clase. La escuela estaba en contacto con el suelo.

Nuevamente aparece aquí la necesidad de vincular al niño con la tierra, con la naturaleza, lo que expresa la impronta dejada por el proyecto de parques-escolares de Vaz Ferreira, aunque también de ciertas iniciativas anteriores que habían tomado como eje las teorías de Federico Fröebel, especialmente en el ámbito de la enseñanza prescolaris. Poco tiempo después, en el año 1928 y ya en el marco de las futuras escuelas experimentales, Scasso debe enfrentar uno de los proyectos más importantes en esta materia: la Escuela Experimental de Malvín. Sobre esta reflexionaría años después:

...comenzamos a trabajar [junto a Olympia Fernández] en la escuela. La proyecté con la particularidad de estar dividida en pabellones, en contacto con la naturaleza. En lugar de la escuela para el gran número de alumnos, la planteamos a la escala del niño y del pequeño grupo. Estos pabellones se iban articulando unos con otros, previéndose un área para el edificio de servicios generales que se realizó posteriormente y concediéndose una importancia extraordinaria a los espacios libres. ${ }^{19}$

Otro aspecto debe aquí tenerse en cuenta, en relación a lo planteado por el proyecto de Vaz Ferreira: la resolución de la arquitectura en pabellones separados, como forma de garantir un mayor contacto con el verde y centralizar ciertas actividades comunes en determinado edificio "de servicios generales". No obstante, Scasso refiere también a lo importante de una adecuada escala, más propia del niño y que, precisamente, se logra mediante la tipología de pabellón; pero también entiende necesario un número alternativo de alumnos en relación al proyecto de Vaz Ferreira. En apoyo a la escala infantil y en concordancia con los nuevos métodos pedagógicos establece importantes consideraciones respecto de los espacios interiores, fundamentalmente en materia de aulas y equipamiento:
El salón de clases estaba constituido de la siguiente manera: no ya el salón rectangular, el salón profundo con la maestra al frente y los bancos que se iban extendiendo hacia el fondo, como en la escuela clásica, sino el salón cuadrado, con total disposición de los bancos individuales. Todo lo que tenía pared llena, eran pizarrones a la altura del niño de modo que todos dibujaban o escribían al mismo tiempo, pues el sistema pedagógico así lo establecía. ${ }^{20}$

Se elimina la forma tradicional de alineación de bancos por lo que Scasso sostiene: "como corresponde al sistema pedagógico decrolyano, no existen bancos que conserven una disposición inmutable y rígida, como en la escuela tradicional; solo existen las mesas de labor colectiva." ${ }^{21 .}$ Las transformaciones funcionales podían alcanzar hasta las propias circulaciones, las que llegaban a adquirir verdadero carácter lúdico. Los dos

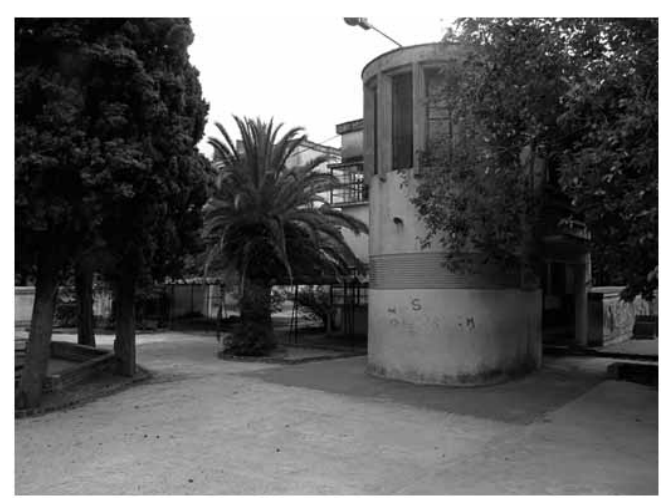

Fig. 10. Escuela Experimental de Malvín. Arq. Juan Scasso. Fotografía de Juan Ángel Urruzola

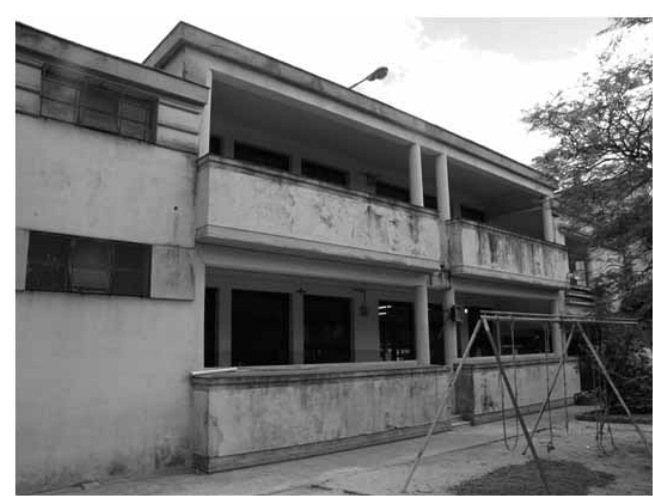

Fig. 11. Escuela Experimental de Malvín. Arq. Juan Scasso. Fotografía de Juan Ángel Urruzola 
niveles en que se organizaban los pabellones de aulas podían sortearse, al bajar, mediante toboganes en carpintería que promovían la alegría y el juego permanente de los niños (Figs. 10 y 11).

A esta escuela experimental le siguió otra en la ciudad de Las Piedras, Canelones, aunque

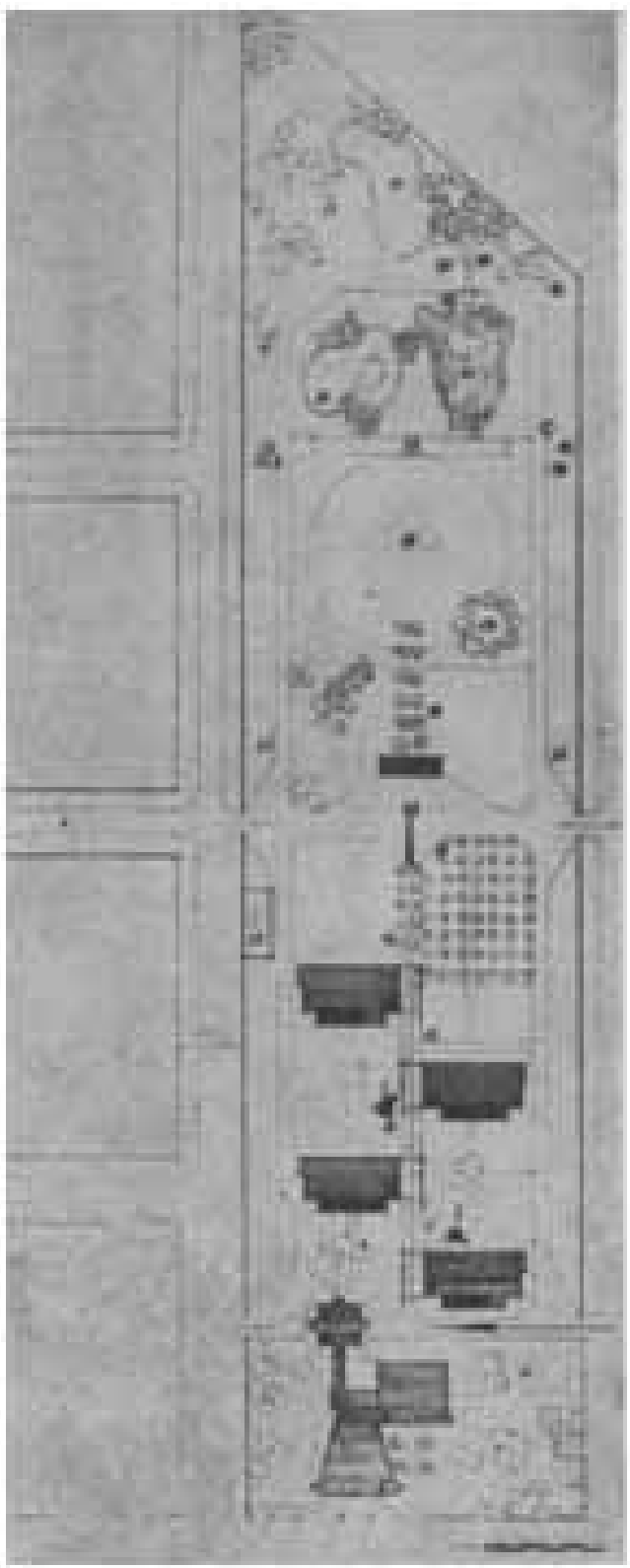

Fig. 12. Escuela Experimental de Las Piedras. Anteproyecto del Arq. Juan Scasso. Planta general y ubicación de edificios de características diferentes, incluso en materia pedagógica. También proyectada por Scasso, su edificación contó con menos recursos ya que se trataba de un período de crisis, hacia el año 1931. Se trabajó asimismo con la idea de pabellones insertos en el verde, donde sus espacios estructuradores internos serían el aula, el laboratorio y el taller. Según Scasso "el aula era la expresión abstracta, el laboratorio la preparación y el taller la expresión concreta, pasando el niño de uno al otro" ${ }^{22}$. La escuela contaba con un jardín botánico y un espejo de agua recordando, en cierta forma, las premisas de los parques escolares. Separado de los pabellones se realizaría luego la edificación de un comedor y una sala de actos, también proyectada por el mismo Scasso (Figs. 12, 13, 14 y 15).

A diferencia de la escuela de Malvín, la respuesta formal resulta - aunque indiscutiblemente moderna - algo evocativa de la tradición rural, con un manejo de cubiertas inclinadas en pabellones y una propuesta bastante más rupturista en el diseño del edificio comedor, el que respondía en cambio a una planta de tipo estrellada ${ }^{23}$.

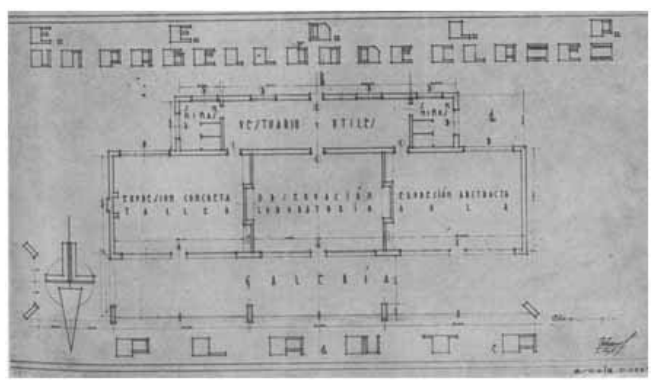

Fig. 13. Escuela Experimental de Las Piedras. Pabellón de clases. Arq. Juan Scasso. Dibujo Testimonial

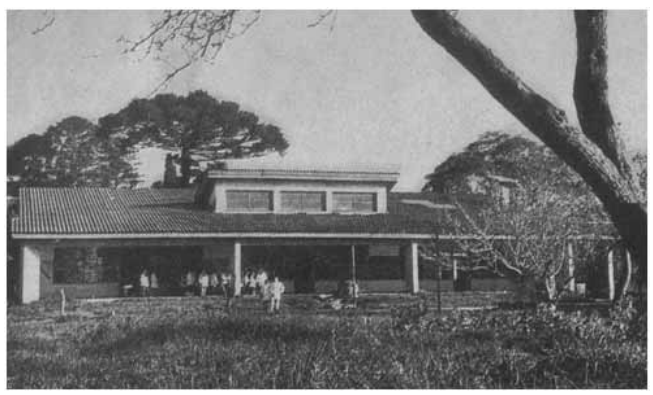

Fig. 14. Escuela Experimental de Las Piedras. Pabellón de clases Arq. Juan Scasso. Fotografía testimonial 


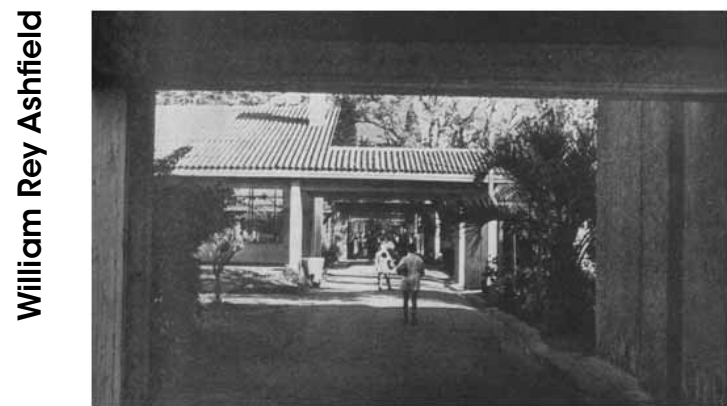

Fig. 15. Escuela Experimental de Las Piedras. Pabellón de clases. Arq. Juan Scasso. Fotografía testimonial

\section{La colmena social}

La enseñanza fue considerada en Uruguay, durante las primeras décadas del siglo XX, un pivot central dentro del discurso político y social. En una concepción alineada con el concepto de progreso, los patrones y métodos de transformación real podían - o incluso debían - estar cercanos a la idea de lo utópico. Se trataba de una enseñanza entendida como "humanística y universalista", cuyas arquitecturas se abrían "hacia el exterior" y la escuela, muy en particular, se "integraba en sí misma y con la colectividad". ${ }^{24}$

Este concepto de integración, precisamente, será un eje de enorme importancia conceptual en la arquitectura moderna uruguaya: integración al contexto, integración con las artes visuales, integración en sociedad ${ }^{25}$. En este último sentido es que debe verse, por sobre todo, el compromiso de la arquitectura moderna con los programas escolares, y su dimensión más utópica. La escuela buscará ser - y de hecho lo fue - un factor clave en esa integración, durante las primeras décadas del siglo XX.

La idea de una "colmena social" 26 ejerció de metáfora referencial en distintos discursos acer- ca de la institución escolar. En su relacionamiento con la naturaleza la escuela debía ser el lugar de una nueva polinización, desde donde surgiría una sociedad integrada y, por tanto, un hombre individualmente mejor. La naturaleza era entendida como lugar de búsquedas autónomas e individuales, donde el niño - como la abeja se enfrentaría a ella a través de una experiencia directa, reconociendo sus accidentes y dificultades, su superficie rústica y compleja. El aula en cambio, sería el espacio donde reconocer y asimilar esa experiencia; una verdadera osatura de lógica colmenar en que los alumnos participarían de un estratégico plan funcional, de mejor acceso al conocimiento. Una definición dada por el arquitecto J. H. Domato - socio principal de Juan Scasso -, en relación a las escuelas experimentales advertía ya esta metáfora apícola:

Desde la célula refugio, con su fin dentro del organismo, hasta el gran salón de actos, de alta significación con el todo, comprendiendo toda la masa edificada, movida armónicamente con la vinculación propia de su funcionamiento y el espacio libre distribuido de manera racional, todo debe responder a un plan funcional. ${ }^{27}$

Lo anterior constituye una muestra de una modernidad integral e integradora, triunfante en el Uruguay de la primera mitad del siglo XX. No se trató de una modernidad de epitelio, de cáscara formal, de adopción de simples modos o tics, sino de una arquitectura moderna con base conceptual (en términos programáticos) y visual (en términos formales, materiales y simbólicos), que manifestó una adscripción firme a lo nuevo. Una modernidad, por tanto, que nunca descartó la visión utópica ni el desafío de revertir los órdenes hegemónicos - o al menos, más tradicionales - en programas de primera importancia como lo fue, sin duda, la enseñanza. 


\section{NOTAS}

${ }^{1}$ Tomaré como válida y acertada la distinción conceptual entre los términos utopía e ideología, que planteara Karl Mannheim, en su ya clásico libro: Mannheim, K.. Ideología y Utopía. Introducción a la sociología del conocimiento, Fondo de Cultura Económica, México, 1993.

2 Se trataba de los edificios del Hospital de Clínicas y del Instituto Experimental de Higiene. Se agregaría, en forma siguiente, el edificio del Instituto Nacional de Traumatología. Todos ellos se concibieron bajo la impronta de un fuerte compromiso moderno, tanto programático como formal.

${ }^{3}$ Ver esta negación de lo utópico en: Arana, Mariano y Garabelli, Lorenzo, Arquitectura renovadora en Montevideo 1915-1940, Fundación de Cultura Universitaria, Montevideo, 1995.

4 Scasso, J., "Un problema social: El empleo de las horas libres en la ciudad", Arquitectura, N 217, Montevideo, 1947.

${ }^{5}$ Vaz Ferreira, C., "Parques escolares", en Lecciones sobre pedagogía y cuestiones de enseñanza, Tomo XVI, vol. 3, Cámara de Representantes, Montevideo, 1957, pág. 159.

6 Ya en 1904, Vaz Ferreira había planteado la necesidad de crear una escuela-parque para 10. 000 alumnos - o en su defecto dos de 5000 -, en la periferia urbana de Montevideo. Tal iniciativa, aunque entonces no encontró oposiciones firmes fue desconsiderada. En 1913, retomó el tema de los parques escolares con una propuesta que daba especial solución a la cuestión del transporte en función de la aparición del tranvía eléctrico en la escena urbana. Más tarde aun, en 1923, desarrolló nuevamente su idea siendo publicada en diversos medios de prensa, pero con escaso éxito.

${ }^{7}$ Puede leerse el cuerpo argumentativo de este proyecto en un documento impreso, presentado al Tercer Congreso Panamericano de Arquitectos en Buenos Aires: Capurro, Fernando, Parques Escolares, Dirección de Arquitectura, Ministerio de Obras Públicas, Montevideo, 1927, pág. 13.
${ }^{8}$ Guillot Muñoz, Álvaro y Gervasio, "Le Corbusier en Montevideo", Revista Cruz del Sur, № Enero/febrero 1930, Montevideo, pág. 14.

${ }^{9}$ Capurro, Fernando, Op cit., pág 14.

${ }^{10}$ Capurro, Fernando, Op cit., pág 14.

${ }^{11}$ Guillot Muñoz, Álvaro y Gervasio, Op cit., pág. 14.

12 Esta ley, aprobada en 1928, tendría una importante incidencia en la transformación de los tipos edilicios, ya que exigiría el contacto directo con el aire y la luz de todos los espacios habitables de la vivienda. Sería el comienzo del fin para ciertas tipologías introvertidas, en base a patios, tal como lo era la llamada casa estándar. Asimismo, esta ley definiría un crecimiento paulatino de los tipos extrovertidos, de muy diferente organización y características en relación a la ocupación del padrón y en cuanto a la morfología resultante dentro de la manzana.

${ }^{13}$ Conferencia dictada el 29 de abril de 1927. Vaz Ferreira, Carlos, Parques Escolares, Editorial Gutemberg, Montevideo, pág. 18.

${ }^{14}$ En un folleto, publicado por su hija Matilde Vaz Ferreira de Durruty, en 1981, en la introducción al mismo, Dora Isella Russell afirma: "...al igual que sus hermanos - como antes su padre y su hermana María Eugenia - [Matilde, hija de Vaz Ferreira] no concurrió a ninguna escuela, compartiendo las enseñanzas que les impartía su madre, maestra briIlante...". Vaz Ferreira de Durruty, Matilde, Recuerdos de mi padre, Monteverde y Cía, Montevideo, 1981, pág. 7.

${ }^{15}$ Decía Matilde Vaz Ferreira: Mi padre amaba mucho la naturaleza. Admiraba sus manifestaciones a las cuales, a veces consideraba como presagios. (...) Conocido es el cariño que profesaba a las plantas y cuan sincero era el que sintió por una glicina que extendía sus innumerables brazos frente al antiguo escritorio de su quinta de Atahualpa, que hizo desviar a la línea de edificación varios metros (...). Sentía una gran predilección por todo lo silvestre y agreste". Las características del jardín de la Quinta de Vaz Ferreira encuentra amplias similitudes con el concepto de "jardín en movimiento" del que habla el francés Gilles Clement. Vaz Ferreira de Duruty, Matilde, Op. cit., pág. 17.

16 Scasso, J., "Las escuelas experimentales de Malvín y Las Piedras", Revista de la Facultad de Arquitectura, $\mathrm{N}^{\circ}$ 6, 1965, Montevideo, pág. 50.

${ }^{17}$ Es necesario recordar también, en esta iniciativa, la figura del Dr. Ghigliani, quien desde un cargo directriz, fue también un entusiasta de la idea. Junto a Olympia Fernández formará una comisión de escuelas experimentales, para poner en práctica, de manera paralela a la escuela oficial, los nuevos métodos pedagógicos.

18 Se destaca, en este sentido, la labor pedagógica desarrollada por Enriqueta Compte y Riqué, quien se había compenetrado de las enseñanzas de Fröebel en Europa. Dichas teorías fueron introducidas por esta pedagoga en forma manera temprana - 1890 - en Uruguay. El valor del juego libre y del uso de los sentidos en el proceso de enseñanza resultaría un factor clave para el contacto temprano del niño con la naturaleza.

${ }^{19}$ Scasso, J., Op. cit., pág. 50.

${ }^{20}$ Scasso, J., Op. cit., pág. 50.

21 Scasso, J., "La Escuela Experimental de Malvín", Arquitectura, MayoJunio 1932, SAU, Montevideo.

22 Scasso, J., Op. cit., pág. 51.

${ }^{23}$ Al respecto dice Scasso: ". . .el comedor lo imaginé como una gran jaula de cristales, con una forma abierta similar a una estrella. Es interesante observar como dentro de la modestia del planteo, cambiándolos techos de modo que tuvieran pendientes hacia lados opuestos, se lograba una cosa muy interesante, muy variada, muy movida y relacionada con el lugar.". Scasso, J., Op. cit., pág. 51.

${ }^{24}$ Scasso, J., Op. cit., pág. 51.

${ }^{25}$ Rey Ashfield, William, Arquitectura Moderna en Montevideo. 19201960, Udelar, CSIC, 2012, pág. 91.

${ }^{26}$ Rey Ashfield, William, Op. cit., pág. 119.

27 Domato, J. H., "Los parques escolares", Arquitectura, Mayo-Junio 1932, SAU, Montevideo, pág. 109. 